\title{
ICP/XRF Analysis for Trace Elements in Soil Samples from Gezira and Suki Schemes, Sudan
}

\author{
Marwa M. Adam ${ }^{1}$, Mustafa. M. Osman ${ }^{2}$, Ahmed. S. Elhag ${ }^{2}$ and Mohamed. A. Elsheikh ${ }^{2}$ \\ ${ }^{1}$ Ministry of Energy \& Oil, Sudanese Petroleum Cooperation, Petroleum Laboratories for Research and \\ Studies Khartoum P.O. Box 2986, Sudan \\ ${ }^{2}$ Chemistry and Nuclear Physics Institute, Sudan Atomic Energy Commission P.O. Box 3001 Khartoum, \\ Sudan
}

\begin{abstract}
In the present study, soil samples have been collected from two different agriculture areas: Gezira and Suki schemes in Sudan. The elemental concentrations for $\mathrm{Cr}, \mathrm{Ni}, \mathrm{Cu}, \mathrm{Zn}$, and $\mathrm{Pb}$ have been determined using Inductively Coupled Plasma Optical Emission Spectrometry (ICP-OES) and X-ray Fluorescence spectrometry (XRF). The accuracy of measurements has been investigated by using ISE (PT) $1 \& 4$ and fortified samples for ICP, IAEA-Soil-7 for XRF, respectively. A good agreement was found between certified and measured values.

The average elemental concentrations by ICP of these elements $\mathrm{Cr}, \mathrm{Ni}, \mathrm{Cu}, \mathrm{Zn}$, and $\mathrm{Pb}$ in $\mathrm{loc}_{1}$ were found as follows: $84.7,48.15,33.5,65.43$, and $12.57 \mathrm{ppm}$, respectively. While the results obtained in $\operatorname{loc}_{2}$ were found as follows: $105,65.1,41.3,55.4$, and $12.74 \mathrm{ppm}$, respectively. The average elemental concentrations by XRF of these elements $\mathrm{Cr}, \mathrm{Ni}, \mathrm{Cu}, \mathrm{Zn}$, and $\mathrm{Pb}$ in $\mathrm{loc}_{1}$ were found as follows: 77.21, 43.72, 27.62, 86.96, and $18.74 \mathrm{ppm}$, respectively. While the results obtained in $\operatorname{loc}_{2}$ were found as follows: 123.33, 57.41, $35.99,98.85$, and $16.43 \mathrm{ppm}$, respectively.

A statistical test (t-test) was applied to the data of both methods without any significant difference between the two techniques. The results obtained were compared to WHO permissible limits. Correlations between different elements were performed. Hierarchical cluster analysis was done for the data. The average elemental concentrations were calculated and compared with data from the literature.
\end{abstract}

Keywords: ICP, XRF, Trace elements, Soil samples, Gezira Scheme, and Suki Scheme.

\section{Introduction}

Trace elements in soils are derived from the weathering of geologic parent materials and tend to be immobile. The concentrations in soils are related to the overlying parent material based on the immobile nature of trace elements. The effects of soil characteristics on trace element concentrations in soils have been studied. In summary, seven factors determine the fate of trace elements in soil: soil $\mathrm{pH}$, cation exchange capacity, anion exchange capacity, organic matter content, clay content and type, oxide content and type, and redox potential (Lepp et al. 1981).

Soil is a natural body, having both mineral and organic components in addition to physical, chemical, and biological properties. Soil properties, therefore, cannot be a simple reflection of the combined properties of all soil components. The composition of soils is extremely diverse and although governed by many different factors, climatic conditions and parent material predominate most commonly. Soil is composed of three phases: (i) solid (mineral and organic), (ii) liquid, and (iii) gaseous, and it exhibits properties resulting from the physical and chemical equilibriums of these phases. Moreover, not only the chemical composition of the solid components of soil but also its mineral structure and the state of dispersion are important factors influencing soil properties. Although trace elements are minor components of the solid soil phase, they play an important role in soil fertility (Kabata-Pendias et al. 2004). 
Knowledge of the association of trace elements with particular soil phases and their affinity to each soil constituent is the key to a better understanding of the principles governing their behavior in soils. The "normal concentrations" of trace elements in soils are of great interest as background values are needed for any assessment of the degree of soil contamination.

Sources of trace elements in agricultural soil are the natural processes of weathering of rocks, aerial transport of volatile compounds, and anthropogenic activities such as combustion of coal and other fossil fuels, mining and smelting of metallic ores, landfills, industrial activities, vehicles emissions, repeated use of metal-enriched fertilizers, pesticides and agro-chemicals, bio-solids, sewage sludge, and wastewater (Ahamed et al. 2008). One of the potential sources of trace elements is phosphate fertilizer that contains $\mathrm{Cd}$, $\mathrm{Se}$, and other trace elements as impurities (i.e., from phosphate rocks). $\mathrm{Cu}, \mathrm{Se}$, and $\mathrm{Zn}$ often are added to animal feeds and are transferred to agricultural soils via animal manure (sheppard et al. 2009).

The total amount of trace elements present in the soil at a particular time depends on how many metals are added to the soil from different media and how much is leached or absorbed by plants and animals (Ogunkunle et al. 2017).

Trace element concentrations significantly differ among both soil groups and geographic regions, this statement indicates that parent material and climatic conditions have predominated impact on the trace element status of soils (Topias et al. 1997). Many analytical methods have been used in soil analysis. ICP and XRF have been successfully used for the determination of the trace element composition of soil samples in this study. These techniques are useful as research tools in this study. The objective of this study was to determine the levels of $\mathrm{Cr}, \mathrm{Ni}, \mathrm{Cu}, \mathrm{Zn}$, and $\mathrm{Pb}$ in soil samples, to compare the elemental concentrations to WHO permissible limits, and compare the elemental concentrations obtained with data from the literature.

\section{Materials and methods \\ 1.1 Study Area}

The Gezira scheme is one of the largest irrigation projects in the world. Water from the Blue Nile is distributed through canals and ditches to tenant farms lying between the Blue and White Nile rivers. Suki scheme was established upstream from Sinnar to grow cotton, sorghum, and oilseeds. Figure 1 Shows Gezira and Suki Schemes.

\subsection{Sample collection}

Surface soil samples were collected from 0-15 cm depth, from near-surface soil was accomplished with a stainless steel trowel. The surface was dressed (scraped) to remove smeared soil. This is necessary to minimize the effects of contaminant migration interferences due to the smearing of material from other levels, mix thoroughly to obtain a homogenous sample representative of the entire sampling interval, the material in the sample pan was divided into quarters, and each quarter was mixed individually. Two quarters were then be mixed to form halves. The two halves were mixed to form a homogenous matrix. This procedure was repeated several times until the sample is adequately mixed. 20 cores composited to produce one sample that collected in a zig-zag pattern across the field. 20 samples were taken from surface soil from Gezira and Suki schemes. A representative sample of the entire sampling interval and the samples were dried, grinded, passed through $180 \mu \mathrm{m}$ sieve, and placed in plastic bags, stored at room temperature prior to analysis.

\subsection{Sample Preparation}

For ICP analysis, $0.5 \mathrm{~g}$ of each sample was placed into a $14 \mathrm{~mm}$ diameter polyethylene tube, $8 \mathrm{ml}$ of $\mathrm{HNO}_{3}$ $65 \%, 5 \mathrm{ml}$ of $\mathrm{HCl} 37 \% 5 \mathrm{ml}$ of $\mathrm{H}_{3} \mathrm{BO}_{3} 5 \%$ were added. All samples were placed in a rotary shaker for 40 minutes. After the extraction procedure, the solution was filtered by using Whatman42, ash-less, filter paper ( $125 \mathrm{~mm}$ diameter) in a $100 \mathrm{ml}$ volumetric flask. Purified water of $18.2 \mathrm{M} \Omega / \mathrm{cm}$ was used to complete the volume up to $100 \mathrm{ml}$. The final solution was placed in a high-density polyethylene bottle (HDPE) labeled, and stored (Evans et al. 1998).

For XRF analysis, $1 \mathrm{~g}$ of each sample was accurately weighed and pressed into a pellet with an area of 4.1 $\mathrm{cm}^{2}$ using 15 tons pressing machine. 


\subsection{ICP \& XRF measurements}

The elemental concentrations of $\mathrm{Cr}, \mathrm{Ni}, \mathrm{Cu}, \mathrm{Zn}$, and $\mathrm{Pb}$ were determined by inductively coupled plasma optical emission spectrometry. Table 2 shows the accuracy results using ISE (PT) $1 \& 4$ and fortified sample for ICP. In addition, XRF was used to determine the same elements in soil samples. EDXRF provides a rapid and non-destructive method. All measurement was carried out using X-Supreme8000 Spectrometer with an X-ray tube as a source for excitation. The characteristic X-rays emitted from the sample were detected using Silicon Drift Detector (SDD) with Full Width at Half Maximum intensity (FWHM) equal 170 $\mathrm{eV}$ at $5.96 \mathrm{keV}$, each spectrum was collected for a lifetime of 300s. Experimental parameters were obtained by calibration, using standard reference material. The X-Supreme is designed for full treatment dealing with spectra was recorded.

To evaluate the quality of the analytical results obtained by XRF, the IAEA Standard Reference Material (IAEA-soil-7) was analyzed. Table 3 shows the accuracy results using SRM (IAEA soil-7) for XRF.

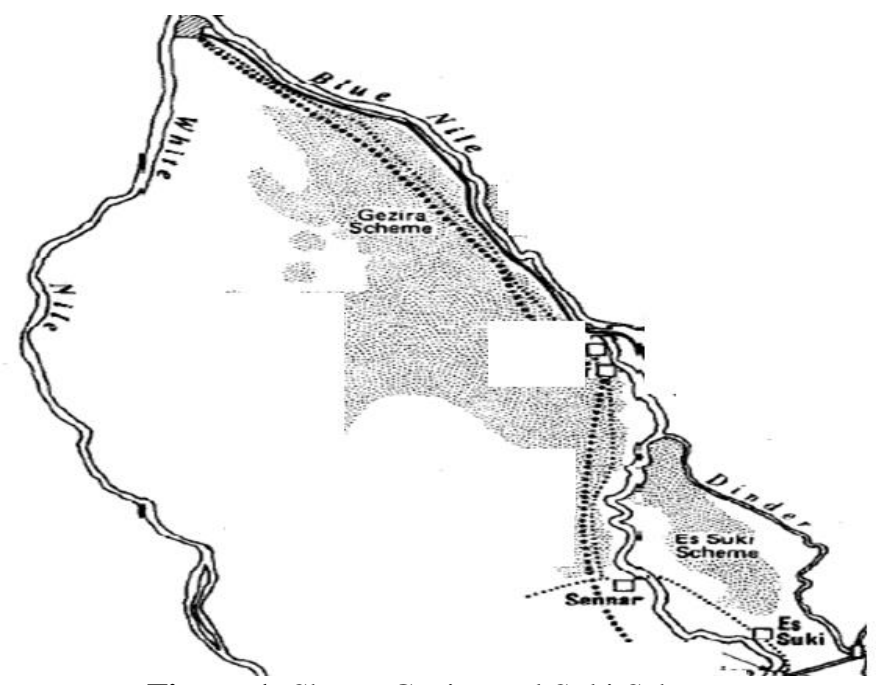

Figure 1: Shows Gezira and Suki Schemes.

Table 2: The accuracy results using ISE (PT) $1 \& 4$ and fortified sample for ICP

\begin{tabular}{|c|c|c|c|c|c|c|}
\hline & \multicolumn{2}{|c|}{ ISE (PT) .1} & \multicolumn{2}{c|}{ ISE (PT). 4} & \multicolumn{2}{c|}{ Fortified sample } \\
\hline & This work & Certificate value & This work & Certificate value & Measured & Spiked \\
\hline $\mathrm{Cr}$ & $35.62 \pm 2.31$ & $32.62 \pm 2.42$ & $48.01 \pm 3.59$ & $48.48 \pm 5.75$ & 425.9 & 400 \\
\hline $\mathrm{Ni}$ & $21.69 \pm 0.85$ & $26.34 \pm 4.96$ & $19.50 \pm 0.99$ & $30.23 \pm 2.42$ & 410.3 & 400 \\
\hline $\mathrm{Cu}$ & $15.19 \pm 0.22$ & $15.15 \pm 1.37$ & $11.81 \pm 0.92$ & $13.27 \pm 1.33$ & 427.1 & 400 \\
\hline $\mathrm{Zn}$ & $56.10 \pm 6.9$ & $52.24 \pm 4.36$ & $129.9 \pm 9.69$ & $85.92 \pm 4.25$ & 819.6 & 800 \\
\hline $\mathrm{Pb}$ & $17.17 \pm 1.06$ & $17.33 \pm 1.55$ & $33.64 \pm 3.25$ & $30.60 \pm 4.18$ & 830.2 & 800 \\
\hline
\end{tabular}

Table 3: The accuracy results using SRM (IAEA soil-7) for XRF

\begin{tabular}{|c|c|c|c|}
\hline Elements & Certified values & Measured values & Relative error (\%) \\
\hline $\mathrm{Cr}$ & $60 \pm 21$ & $53.84 \pm 12.9$ & 10 \\
\hline $\mathrm{Ni}$ & $26 \pm 6.9$ & $22.37 \pm 18.5$ & 14 \\
\hline $\mathrm{Cu}$ & $11 \pm$ & $9.81 \pm 13.4$ & 11 \\
\hline $\mathrm{Zn}$ & $104 \pm$ & $99.93 \pm 6.7$ & 4 \\
\hline $\mathrm{Pb}$ & $60 \pm 13$ & $52.24 \pm 15.5$ & 13 \\
\hline
\end{tabular}

\section{Results and Discussion}

\subsection{Elemental concentrations for soil samples by ICP and XRF}

Elemental concentrations for soil samples were analyzed by ICP and XRF. Summary of statistical data for elemental concentrations (ppm) in soil samples from $\mathrm{Loc}_{1}$ and $\mathrm{Loc}_{2}$ by ICP and XRF are listed in Tables (4, 5) respectively and graphically displayed in Figure (2). The relationships between obtained results of the investigated elements by both techniques (ICP/XRF) are illustrated in Figure (3).

In $\operatorname{loc}_{1}$, the results obtained by ICP were showed that the concentration of $\mathrm{Cr}$ ranges from $78.6 \mathrm{ppm}$ to 90.9 ppm with an average value of $84.7 \mathrm{ppm}$ and a standard deviation value of $6.1 \mathrm{ppm}$. Nickel concentration ranges from $44.3 \mathrm{ppm}$ to $51.8 \mathrm{ppm}$ with an average value of $48 \mathrm{ppm}$ and a standard deviation value of 3.8 ppm. Copper, concentration ranges from $30.8 \mathrm{ppm}$ to $36.3 \mathrm{ppm}$ with an average value of $33.5 \mathrm{ppm}$ and a standard deviation value of $2.8 \mathrm{ppm}$. The concentration of zinc ranges from $58 \mathrm{ppm}$ to $72.9 \mathrm{ppm}$ with an 
average value of $65.4 \mathrm{ppm}$ and a standard deviation value of $7.5 \mathrm{ppm}$. Lead concentration ranges from 9.4 ppm to $15.8 \mathrm{ppm}$ with an average value of $12.6 \mathrm{ppm}$ and a standard deviation value of $3.2 \mathrm{ppm}$. While the results obtained by XRF for the same samples showed that the concentration of Cr ranges from $66.7 \mathrm{ppm}$ to $88.2 \mathrm{ppm}$ with an average value of $77.21 \mathrm{ppm}$ and a standard deviation value of $7.76 \mathrm{ppm}$. Nickel concentration ranges from $42.29 \mathrm{ppm}$ to $44.77 \mathrm{ppm}$ with an average value of $43.72 \mathrm{ppm}$ and a standard deviation value of $0.90 \mathrm{ppm}$. Copper, concentration ranges from $25.8 \mathrm{ppm}$ to $28.4 \mathrm{ppm}$ with an average value of $27.63 \mathrm{ppm}$ and a standard deviation value of $0.73 \mathrm{ppm}$. The concentration of zinc ranges from 64.8 ppm to $81 \mathrm{ppm}$ with an average value of $68.96 \mathrm{ppm}$ and a standard deviation value of $4.81 \mathrm{ppm}$. Lead concentration ranges from $15.7 \mathrm{ppm}$ to $20.95 \mathrm{ppm}$ with an average value of $18.78 \mathrm{ppm}$ and a standard deviation value of $1.68 \mathrm{ppm}$.

In $\operatorname{loc}_{2}$, ICP results showed that the concentration of $\mathrm{Cr}$ ranges from $115.5 \mathrm{ppm}$ to $121.7 \mathrm{ppm}$ with an average value of $105 \mathrm{ppm}$ and a standard deviation value of $7.8 \mathrm{ppm}$. Nickel concentration ranges from 63.6 ppm to $69.8 \mathrm{ppm}$ with an average value of $65.1 \mathrm{ppm}$ and a standard deviation value of $2.5 \mathrm{ppm}$. Copper, concentration ranges from $41.1 \mathrm{ppm}$ to $47.3 \mathrm{ppm}$ with an average value of $41.3 \mathrm{ppm}$ and a standard deviation value of $2.9 \mathrm{ppm}$. The concentration of zinc ranges from $58.2 \mathrm{ppm}$ to $64.4 \mathrm{ppm}$ with an average value of $55.4 \mathrm{ppm}$ and a standard deviation value of $5.3 \mathrm{ppm}$. Lead concentration ranges from $11.1 \mathrm{ppm}$ to $17.2 \mathrm{ppm}$ with an average value of $12.7 \mathrm{ppm}$ and a standard deviation value of $1.4 \mathrm{ppm}$. While the results obtained by XRF for the same samples showed that the concentration of $\mathrm{Cr}$ ranges from $109 \mathrm{ppm}$ to 151 $\mathrm{ppm}$ with an average value of $123.3 \mathrm{ppm}$ and a standard deviation value of $15.5 \mathrm{ppm}$. Nickel concentration ranges from $45.9 \mathrm{ppm}$ to $62.07 \mathrm{ppm}$ with an average value of $57.41 \mathrm{ppm}$ and a standard deviation value of $2.36 \mathrm{ppm}$. Copper, concentration ranges from $34.67 \mathrm{ppm}$ to $37.6 \mathrm{ppm}$ with an average value of $35.9 \mathrm{ppm}$ and a standard deviation value of $0.91 \mathrm{ppm}$. The concentration of zinc ranges from $36.54 \mathrm{ppm}$ to $69.2 \mathrm{ppm}$ with an average value of $54.8 \mathrm{ppm}$ and a standard deviation value of $11.7 \mathrm{ppm}$. Lead concentration ranges from $12.72 \mathrm{ppm}$ to $20.03 \mathrm{ppm}$ with an average value of $16.43 \mathrm{ppm}$ and a standard deviation value of 1.85 ppm.

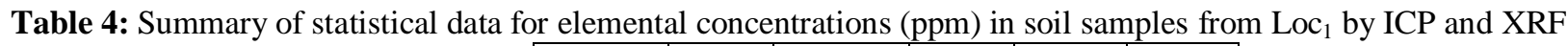

\begin{tabular}{|c|c|c|c|c|c|}
\hline Loc 1 & & Mean & SD & Min & Max \\
\hline \multirow{2}{*}{$\mathrm{Cr}$} & ICP & 84.7 & 6.1 & 78.6 & 90.9 \\
\cline { 2 - 6 } & XRF & 77.21 & 7.76 & 66.7 & 88.2 \\
\hline \multirow{2}{*}{$\mathrm{Ni}$} & ICP & 48.15 & 3.8 & 44.3 & 51.8 \\
\cline { 2 - 6 } & XRF & 43.728 & 0.9 & 42.29 & 44.77 \\
\hline \multirow{2}{*}{$\mathrm{Cu}$} & ICP & 33.5 & 2.8 & 30.8 & 36.3 \\
\cline { 2 - 6 } & XRF & 27.62 & 0.73 & 25.8 & 28.4 \\
\hline \multirow{2}{*}{$\mathrm{Zn}$} & ICP & 65.43 & 7.5 & 58 & 72.9 \\
\cline { 2 - 6 } & XRF & 68.96 & 4.81 & 64.8 & 81 \\
\hline \multirow{2}{*}{$\mathrm{Pb}$} & ICP & 12.57 & 3.2 & 9.4 & 15.8 \\
\cline { 2 - 6 } & XRF & 18.74 & 1.68 & 15.7 & 20.95 \\
\hline
\end{tabular}

Table 5: Summary of statistical data for elemental concentrations (ppm) in soil samples from $\mathrm{Loc}_{2}$ by ICP and XRF

\begin{tabular}{|c|c|c|c|c|c|}
\hline Loc 2 & & Mean & SD & Min & Max \\
\hline \multirow{2}{*}{$\mathrm{Cr}$} & ICP & 105 & 7.8 & 115.5 & 121.7 \\
\cline { 2 - 6 } & XRF & 123.33 & 15.55 & 108.5 & 151.4 \\
\hline \multirow{2}{*}{$\mathrm{Ni}$} & ICP & 65.1 & 2.5 & 63.6 & 69.8 \\
\cline { 2 - 6 } & XRF & 57.41 & 2.36 & 54.99 & 62.07 \\
\hline \multirow{2}{*}{$\mathrm{Cu}$} & ICP & 41.3 & 2.9 & 41.1 & 47.3 \\
\cline { 2 - 6 } & XRF & 36 & 0.91 & 34.67 & 37.6 \\
\hline \multirow{2}{*}{$\mathrm{Zn}$} & ICP & 55.4 & 5.3 & 53.2 & 64.4 \\
\cline { 2 - 6 } & XRF & 54.8 & 11.7 & 36.54 & 69.2 \\
\hline \multirow{2}{*}{$\mathrm{Pb}$} & ICP & 12.74 & 1.4 & 11.1 & 17.2 \\
\cline { 2 - 6 } & XRF & 16.432 & 1.85 & 12.72 & 20.03 \\
\hline
\end{tabular}




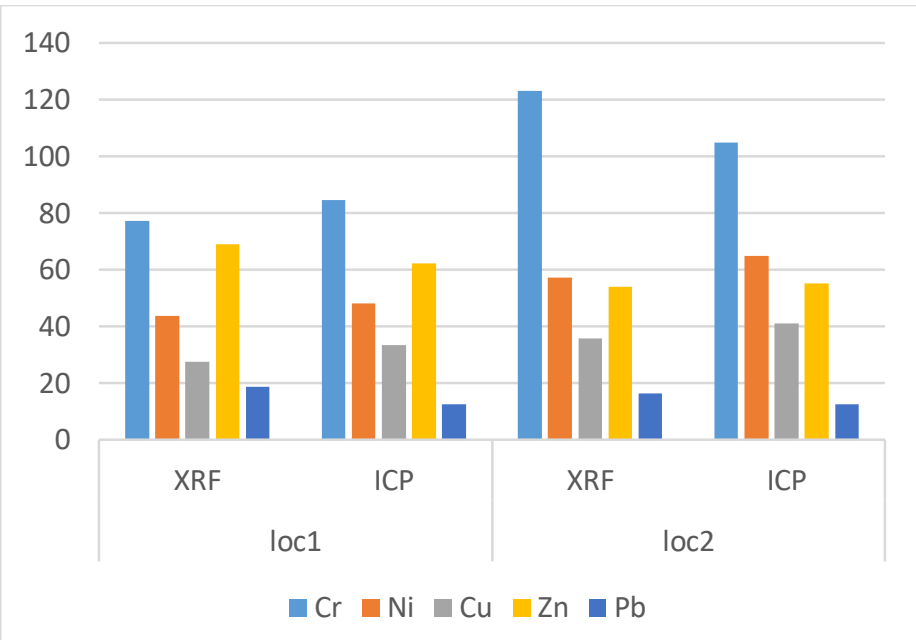

Figure 2: Mean elemental concentrations (ppm) in different locations
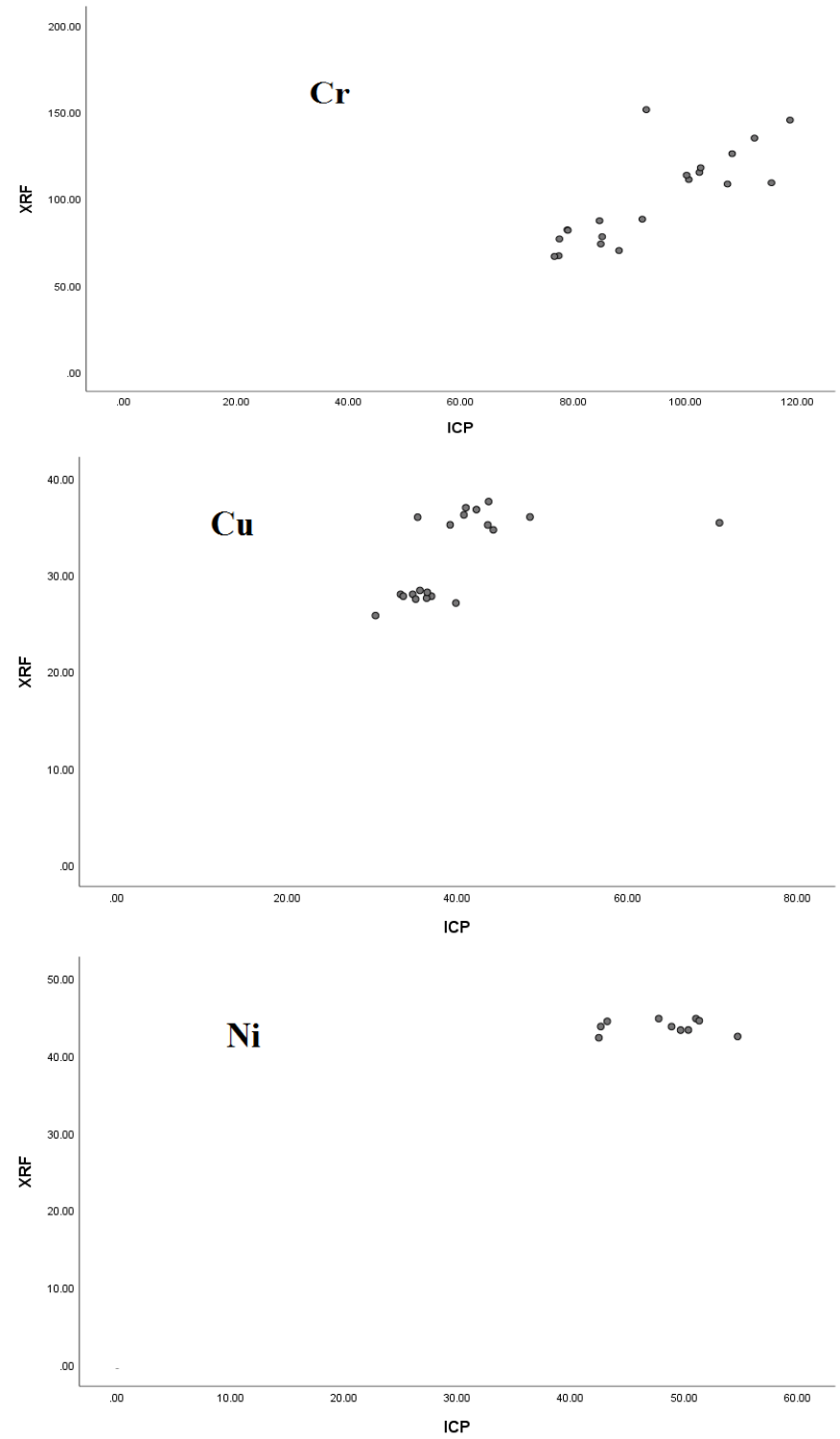

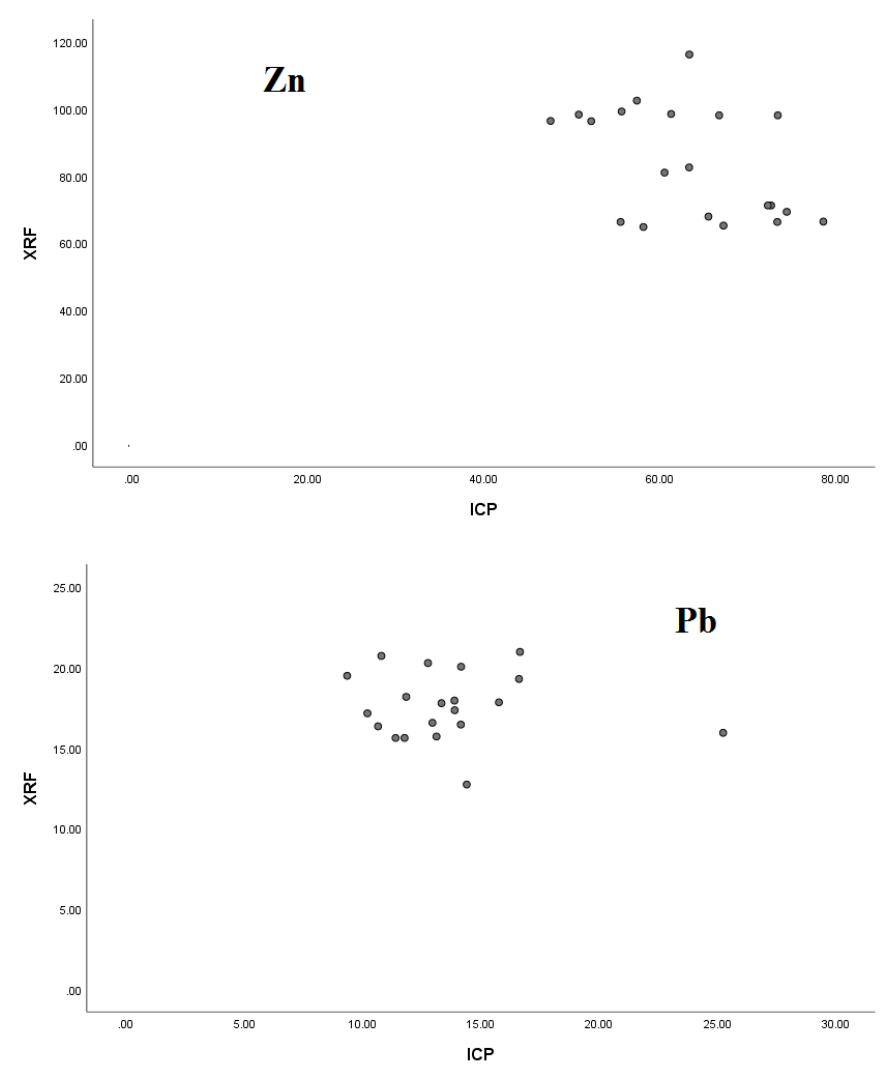

Figure 3: Relationships between obtained results of the investigated elements by both techniques (ICP\&XRF)

A statistical test ( $t$-test) was applied to the data of both methods without any significant difference between the two techniques. From results obtained that the mean elemental concentration of elements was found to be higher in $\operatorname{loc}_{2}$ than $\operatorname{loc}_{1}$ except for $\mathrm{Zn}$ which found higher in $\operatorname{loc}_{1}$ may be due to the use of fertilizers, the different agricultural cycle, types of crops grown in different locations.

$\mathrm{XRF}$ is a multi-element technique, which is theoretically capable of determining an ever-greater range of elements than ICP-OES. ICP-OES is the best method for light elements. XRF is more sensitive to some high mass elements. XRF is a non-destructive method compared to ICP. Consequently, the XRF spectrometer employed is a promising tool that may be used for quick screening analysis of environmental samples without the need for time-consuming sample preparation procedures. Whereas in the case of ICP-OES, sample pretreatment methods depend on the type of soil and the chemical method itself.

\subsection{WHO permissible limits for elements for soil}

The results obtained were compared to WHO permissible limits for elements for soil showed that the values indicate the desirable maximum levels of elements in unpolluted soil except for $\mathrm{Ni}$, which is half-fold higher when compared to the mentioned values (WHO Report, 1989).

\subsection{Correlation}

Correlations between concentrations certain elements can be used as indicators of specific sources (Annegarn et al. 1992). A pairwise correlation was performed. Table 6 shows the correlation between the elemental concentration data for soil samples collected from different locations. The correlation data (bold correlation is significant at $\mathrm{p}<0.05$ ) results showed that are highly correlated with each other.

\subsection{Cluster analysis}

The results of Hierarchical cluster analysis of trace elements in soil samples were obtained as dendograms displaying three main clusters. In the dendogram the first cluster containing the $\mathrm{Ni}$ and $\mathrm{Cu}$. The second cluster includes $\mathrm{Cr}$ and $\mathrm{Zn}$. The third cluster containing only Pb. Figure 4 shows the Hierarchical cluster analysis.

\subsection{Comparison of elemental concentration between this study and data from the literature}


A comparison of the average elemental concentration of soil samples with previous data from literature was listed in Table 7. The average concentration of $\mathrm{Cr}$ was higher in Egypt, Ghana, and this study than the values in India and Burkina Faso. Ni concentrations in India and Ghana are less than the concentration in Ethiopia, Egypt, Burkina Faso, and this study. The concentration of $\mathrm{Cu}$ in Ethiopia, Egypt, Burkina Faso, and this study is higher compared to the India study. The average concentrations of $\mathrm{Zn}$ were higher in Ethiopia, Egypt, India, and this study than the values in Burkina Faso. Lead concentrations in India and Ghana are less than the concentration in Ethiopia, Egypt, Burkina Faso, and this study.

Table 6: Correlation between the analyzed elements

\begin{tabular}{|c|c|c|c|c|c|}
\hline & $\mathrm{Cr}$ & $\mathrm{Ni}$ & $\mathrm{Cu}$ & $\mathrm{Zn}$ & $\mathrm{Pb}$ \\
\hline $\mathrm{Cr}$ & 1 & & & & \\
\hline $\mathrm{Ni}$ & 0.751 & 1 & & & \\
\hline $\mathrm{Cu}$ & 0.592 & 0.886 & 1 & & \\
\hline $\mathrm{Zn}$ & 0.373 & 0.092 & 0.020 & 1 & \\
\hline $\mathrm{Pb}$ & -0.030 & -0.159 & -0.328 & 0.397 & 1 \\
\hline
\end{tabular}

Dendrogram using dverage Linkage (Between Groups)

Rescaled Distance Cluster Combine

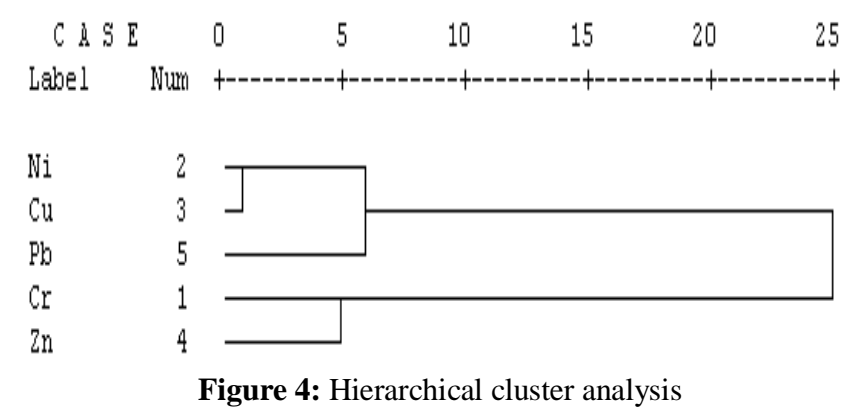

Table 7: Comparison of elemental concentration with data from the literature

\begin{tabular}{|c|c|c|c|c|c|}
\hline & $\mathrm{Cr}$ & $\mathrm{Ni}$ & $\mathrm{Cu}$ & $\mathrm{Zn}$ & $\mathrm{Pb}$ \\
\hline This work & 97.6 & 53.5 & 34.6 & 60.19 & 15.1 \\
\hline India (Sudhakaran et al. 2018) & 47.1 & 14.2 & 11.2 & 35.9 & 11.7 \\
\hline Burkina Faso (Sako et al. 2018) & 28.49 & 42.67 & 34.70 & 4.02 & 15.93 \\
\hline Egypt (Abu Khatita et al. 2020) & 133 & 80.6 & 61.3 & 105 & 19 \\
\hline Ghana (Kazapoe et al. 2019) & 89.52 & 10.97 & - & - & 7.43 \\
\hline Ethiopia (Addis et al. 2017) & - & 103 & 61.75 & 183 & 17 \\
\hline
\end{tabular}

\section{Conclusions}

Elemental concentrations of $\mathrm{Cr}, \mathrm{Ni}, \mathrm{Cu}, \mathrm{Zn}$, and $\mathrm{Pb}$ were analyzed in soil samples using ICP and XRF techniques. The results obtained show no significant difference between both techniques. The elemental concentration of $\mathrm{Cr}, \mathrm{Ni}$, and $\mathrm{Cu}$ in the Suki scheme was found higher than their concentration in the Gezira scheme. While the concentration of $\mathrm{Pb}$ was found to be similar in both locations. The elemental concentration of $\mathrm{Zn}$ in the Suki scheme was found lower than their concentration in the Gezira scheme.

The elemental concentrations were found to be within the WHO permissible limits for analyzed elements in soil except for Ni. XRF spectrometer employed is a promising tool that may be used for quick screening analysis of environmental samples without the need for time-consuming sample preparation procedures. Whereas in the case of ICP-OES, sample pretreatment methods depend on the type of soil and the chemical method itself.

\section{Recommendations}

- Monitoring of trace elements and related indicators periodically in the Gezira and Suki schemes.

- Avoiding the accumulation of these elements by implementing programs such as growing crops, which can reduce the abundance of these elements in the soil.

- Establish a local reference value of concentrations of these elements in agricultural soils. 
- New studies are needed to cover new areas and expanding the sample numbers and increase the sampling depth due to the importance of agriculture in Sudan's economy.

\section{Acknowledgments}

The authors thank the Director of Petroleum Laboratories for Research and Studies (PLRS) Dr. Omer B, Abdlrahim for his support, and permission to publish this paper.

\section{References}

[1] Abu-Khatita A, Koch R, Bamousa AO (2020) Sources identification and contamination assessment of heavy metals in the soil of Middle Nile Delta, Egypt: Journal of Taibah University for Science 14 (1): 750-761.

[2] Addis W, Abebaw A (2017) Determination of heavy metal concentration in soils used for cultivation of Allium sativum L. (garlic) in East Gojjam Zone, Amhara Region, Ethiopia. Cogent Chemistry 3 (1): 1419422. DOI: 10.1080/23312009.2017.1419422.

[3] Ahamed P, Prasad MN (2008) Abiotic Stress Response in Plants; Metabolism, Productivity and Sustainability, eBook (2008) ISBN 978-1-4614-0634-1.

[4] Alina Kabata-Pendias A, (2004) Soil-plant transfer of trace elements-an environmental issue. Geoderma 122 143-149.

[5] Annegarn HJ, Marcaazzan BG, Cereda E, Marchionni M, Zucchiatti A (1992) Sources profiles by unique rations (SPUR) analysis: determination of source profiles from receptor-site streaker sample" Atmospheric. Environment. 26 (A): 333-343.

[6] Kazapoe R, Arhin E (2019) Determination of local background and baseline values of elements within the soils of the Birimian Terrain of the Wassa Area of Southwest Ghana. Geology, Ecology, and Landscapes. DOI:10.1080/24749508.2019.1705644.

[7] Lepp N W (1981) Effect of heavy metals pollution on plants. $1^{\text {st }}$ ed. Applied Sciences Publishers Ltd London.

[8] Ogunkunle CO, Ite AE, Adeniyi SA, Akintola EO, Okere UV (2017) Urban vegetable farming: Anthropic level, bioavailability, and health implication associated with bio accumulated trace metals in selected vegetables in Ilorin, Nigeria. Pollution 3(2): 285-300.

[9] Sheppard S C, Grant CA, Drury CF (2009) Trace Elements in Ontario Soils- mobility, concentration profiles, and evidence of non-point-source pollution. Canadian Journal of Soil Science, 89 (4): 489499.

[10] Sako A, Mamadou Nimi M (2018) Environmental geochemistry and ecological risk assessment of potentially harmful elements in tropical semi-arid soils around the Bagassi South artisanal gold mining site, Burkina Faso. Cogent Environmental Science 4 (1): 1543565.

[11] Sudhakaran M, Ramamoorthy D, Savitha V, Balamuru S (2018) Assessment of trace elements and its influence on Physico-chemical and biological properties in coastal agroecosystem soil, Puducherry region. Geology, Ecology, and Landscapes 2 (3):169-176.

[12] Tobias FJ, Bech J, Algarra PS (1997) Establishment of the background levels of some trace elements in soils of NE Spain with probability plots. Journal of Science of Total Environment 206, 255-265.

[13] World Health Organization (WHO) Report of $33^{\text {rd }}$ meeting, Joint FAO/WHO Joint Expert Committee on Food Additives, Toxicological evaluation of certain food additives and contaminants No. 24, International Programme on Chemical Safety, WHO, Geneva. 21-30 March 1989. Cambridge: Cambridge University Press. https://apps.who.int/iris/handle/10665/41268. 